\title{
Absceso frío en una mano por un hongo dematiáceo. Primera comunicación en Chile de Pleurostomophora richardsiae
}

\author{
Hand cold abscess by a dematiaceous fungus. First report in Chile of Pleurostomophora richardsiae
}

Maira Ferreyra ${ }^{1,2}$, Patricio Godoy², Luis Grau'1,2, Juan Vargas ${ }^{1,2}$, Nicomedes Valenzuela-López y Alberto Fica ${ }^{1,2}$

${ }^{1}$ Hospital Base de Valdivia. Valdivia, Chile.

${ }^{2}$ Facultad de Medicina, Universidad Austral de Chile. Valdivia, Chile.

${ }^{3}$ Facultad de Ciencias de la Salud, Universidad de Antofagasta. Antofagasta, Chile.

Fuente financiamiento: ninguna.

Conflicto de interés: ninguno.

Recibido: 2 de marzo de 2020 / Aceptado: 8 de septiembre de 2020

\section{Resumen}

Los hongos dematiáceos son un grupo heterogéneo de microorganismos capaces de sintetizar melanina. Las infecciones de este grupo que producen hifas en tejidos se denominan feohifomicosis y generalmente afectan la piel y tejidos vecinos. Presentamos el caso de un varón de 86 años con un tumor quístico blando progresivo en su mano y muñeca derecha, no asociado a dolor o signos inflamatorios. Se demostró una tenosinovitis de los flexores con pseudocapsula y sinovitis adherida a los tendones. El cultivo demostró un hongo dematiáceo compatible con Pleurostomophora richardsiae que se confirmó por secuenciación de la región ITS. La biopsia mostró una inflamación crónica granulomatosa e hifas. Después del drenaje quirúrgico, el paciente fue dado de alta sin terapia antifúngica, pero falleció por causas no relacionadas, tres meses después. Esta es la primera descripción de $P$. richardsiae como causa de feohifomicosis en Chile. Esta patología se puede sospechar cuando una lesión quística cutánea crónica involucra extremidades sin signos inflamatorios. Puede afectar a pacientes inmunocompetentes o inmunocomprometidos. El tratamiento contempla la escisión quirúrgica con o sin terapia antifúngica.

Palabras clave: Feohifomicosis; tenosinovitis; granuloma; análisis secuencia ADN; espaciador intergénico ribosomal.

\section{Introducción}

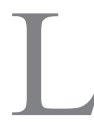

as infecciones de piel y tejidos blandos causadas por bacterias comunes se asocian característicamente a signos inflamatorios como eritema, aumento de volumen, dolor y calor local,

\begin{abstract}
Dematiaceous fungi are a heterogeneous group of microorganisms able to synthesize melanin. Infections by this group that provoke tissular hyphae are called phaeohyphomycosis and usually involve skin and neighbor tissues. We present the case of a 86 years old men with a progressive soft cystic tumor in his right hand and wrist not associated to pain or inflammatory signs. A surgical intervention demonstrated flexor tenosynovitis with serous secretion, pseudocapsule and synovitis. Fungal culture demonstrated a dematiaceous fungi compatible with Pleurostomophora richardsiae that was confirmed by sequencing of the ITS region. Biopsy showed chronic inflammation with granuloma and hyphae. After surgical drainage, the patient was discharged without antifungal therapy but died of unrelated causes three month later. This is the first description of $P$. richardsiae as a cause of phaeohyphomycosis in Chile, a country with a template climate. Phaeohyphomycosis can be suspected when a chronic skin cystic lesion involves extremities without inflammatory signs, sometimes with an associated fistula. It may affect immunocompetent or immunosuppressed patients. Treatment involves surgical excision with or without antifungal therapy and prognosis is favorable.

Keywords: Phaeohyphomycosis; tenosynovitis; granuloma; DNA sequencing analysis; ribosomal intergenic spacer.
\end{abstract}




\section{Caso Clínico}

o enterobacterias), mordeduras de animales (Pasteurella spp), exposición a aguas marinas, peceras o accidentes con espinas de peces (micobacterias y Vibrio spp), co-morbilidades como diabetes mellitus (pie diabético infectado), inmunosupresión o cambios epidemiológicos como la emergencia de infecciones por $S$. aureus resistente a meticilina de origen comunitario (en deportistas, residencias militares o cárceles) o por ciertos serotipos de Streptococcus pyogenes (shock tóxico estreptocócico) ${ }^{3-8}$. En raras ocasiones, estas infecciones pueden asociarse a hongos las que, a diferencia de las infecciones piógenas, tienen un curso indolente y progresivo que dificulta su sospecha. Pleurostomophora richardsiae, antiguamente Phialophora richardsiae, es un hongo ambiental que puede originar infecciones subcutáneas sin manifestaciones inflamatorias locales. Presentamos el caso de un varón con un tumor quístico de una mano que desarrolló una feohifomicosis por $P$. richardsiae secundaria a una inoculación con una breve revisión del tema.

\section{Caso clínico}

Varón de 86 años, residente en la Región de Los Ríos de Chile, con antecedentes de una amputación traumática de la falange distal del dedo mayor y anular de la mano derecha a los 21 años de edad, sin complicaciones posteriores. Padecía de una hipertensión arterial en tratamiento farmacológico y enfermedad renal crónica etapa III (filtración glomerular $34 \mathrm{ml} / \mathrm{min}$ ). No tenía antecedentes de inmunosupresión ni recibía terapia corticoesteroidal. Consultó por un aumento de volumen de la mano y muñeca derecha de tres meses de evolución que se inició en el dedo mayor, sin signos inflamatorios ni fiebre. El paciente refirió haberse efectuado una punción sin técnica aséptica, con salida de material al parecer purulento. Una ecografía mostró un aumento de volumen en relación con los tendones flexores de la mano, sugiriendo una tenosinovitis supurada del antebrazo y la región palmar derecha con aumento de flujo al Doppler, distensión de la vaina tendinosa, presencia de áreas heterogéneas y zonas fluctuantes hipoecogénicas que distendían la vaina sinovial de los tendones flexores. Se derivó a nuestro hospital constatándose el aumento de volumen de la mano derecha y tercio distal del antebrazo derecho por la cara palmar, rigidez articular y la presencia de úlceras de 0,2 mm secundaria a la punción con intención evacuadora en su domicilio, en la región lateral distal del dedo anular derecho con eritema local y secreción purulenta. No se pesquisaron otras anomalías en el examen físico. Los exámenes de laboratorio demostraron un valor de PCR, eritrosedimentación y recuento de leucocitos normal, con una anemia normocítica leve (11,3 g/dl). En el estudio radiológico convencional no se observó compromiso óseo, pero la resonancia magnética reveló un edema óseo del radio, la ulna, huesos del carpo y región proximal de los metacarpianos junto a una tenosinovitis extensa de los flexores de la mano y la muñeca con engrosamiento sinovial que resaltaba con gadolinio, junto a cambios inflamatorios en relación al VI compartimento extensor de la muñeca (Figura 1A-D).

Un cultivo local de las úlceras distales indicó la presencia de Staphylococcus warnerie y Klebsiella oxytoca que se interpretaron sin valor patogénico y el paciente no recibió tratamiento antibacteriano. Posteriormente, se efectuó un aseo quirúrgico con un abordaje por la cara anterior de la muñeca (espacio de Parona) identificándose una gruesa pseudocapsula de la vaina sinovial con salida de abundante líquido seroso turbio, sinovitis adherida a flexores, pero sin lesión de éstos. Se tomó un cultivo corriente y de micobacterias, además de una biopsia de tejido sinovial y pseudocapsula. Desde el postoperatorio y en espera de los cultivos, el paciente recibió ceftriaxona ( $1 \mathrm{~g}$ cada $12 \mathrm{~h}$ ) con clindamicina (600 $\mathrm{mg} \mathrm{c} / 8 \mathrm{~h}$ ) intravenosa por 7 días, sin

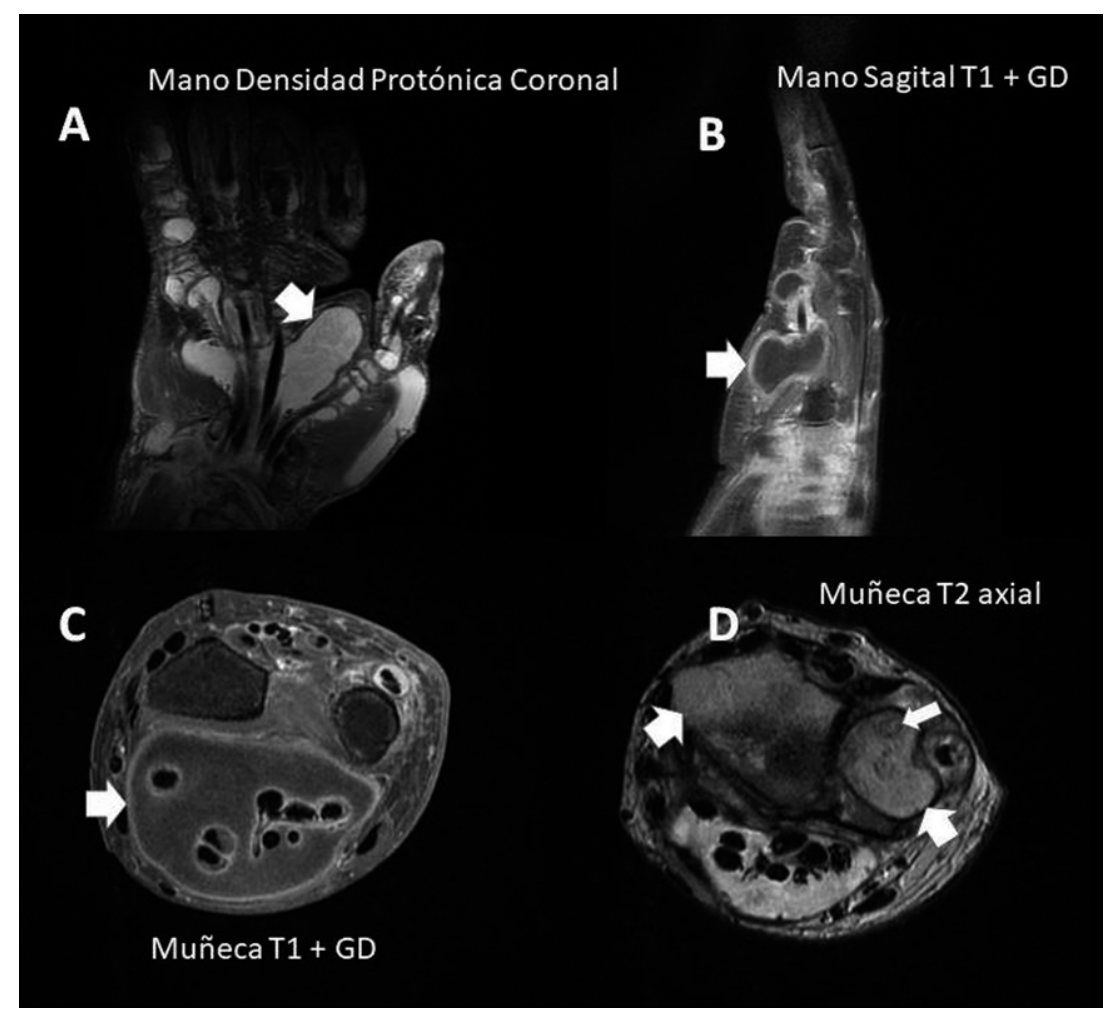

Figura 1. A. Resonancia magnética de mano en proyección coronal con protocolo densidad protónica. Se observa extensa colección que compromete los tendones flexores desde la muñeca hacia la mano (flecha). B. Señal T1 con gadolinio (GD) en proyección sagital. La colección presenta una cápsula irregular que se impregna con contraste compatible con una tenosinovitis (flecha). C. Resonancia magnética de muñeca, señal T1 con GD que muestra una colección líquida que rodea los tendones del plano flexor y que se extiende de la muñeca hacia la mano. Presenta una cápsula irregular que se impregna con contraste (flecha). D. Señal T2, edema óseo que compromete el extremo distal del radio y de la ulna (flechas gruesas). Nótese los fenómenos erosivos fundamentalmente a nivel de la epífisis de la ulna (flecha delgada). 


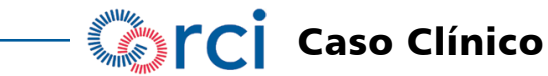

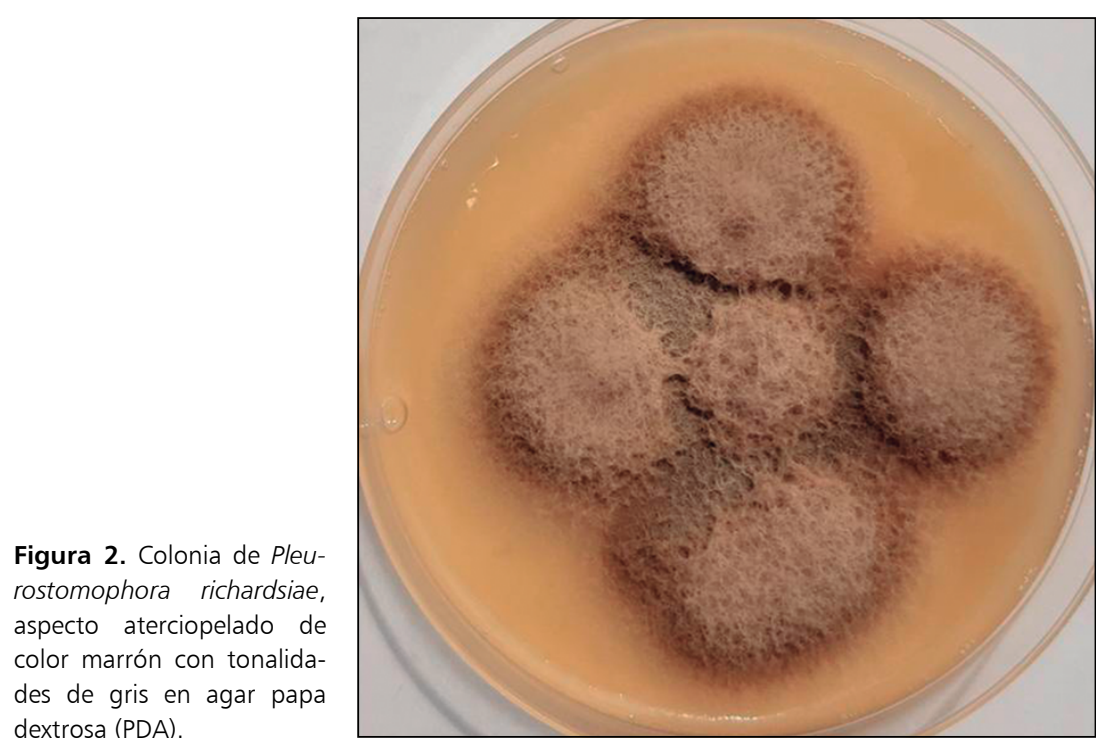

dextrosa (PDA)

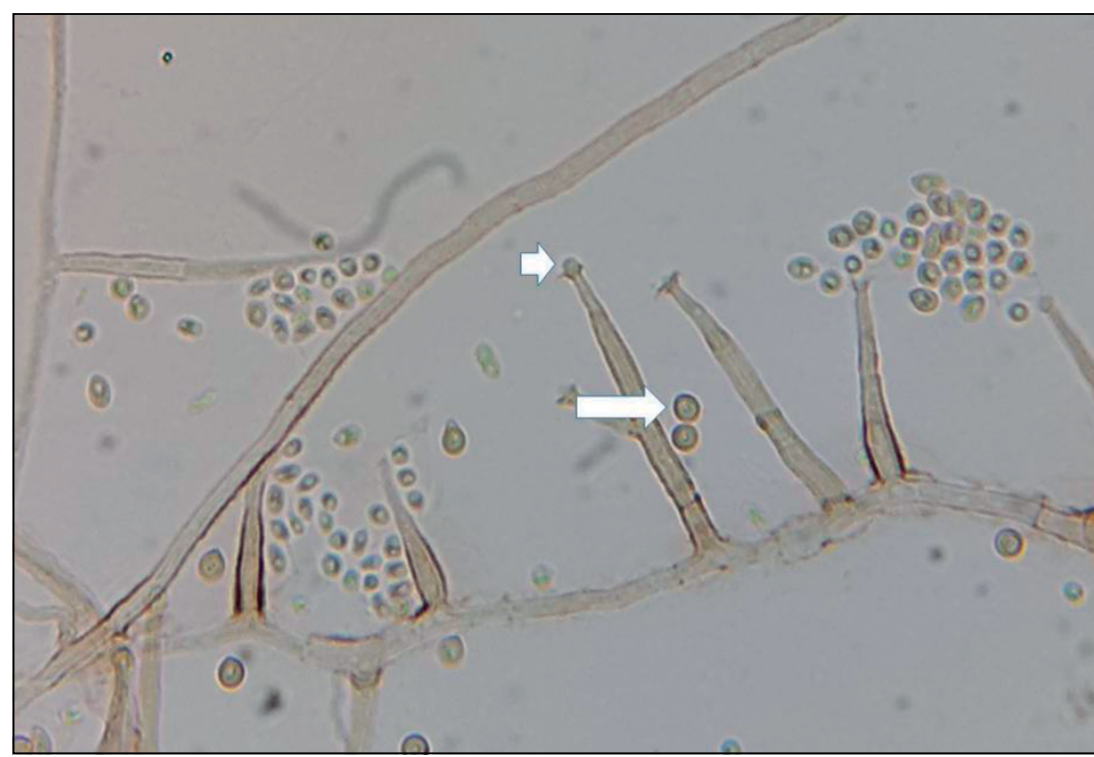

Figura 3. Microfotografía donde se observan conidióforos con fiálides acampanadas pequeñas (flecha corta) y de una tonalidad más oscura, además se observan conidios (flecha larga) redondos oscuros y conidios ovoides más hialinos (aumento de 1.000X).

cambios locales. Posteriormente, el tratamiento se cambió a cefazolina por siete días adicionales por la identificación de $S$. capitis (multisusceptible) en el cultivo de tejido y posteriormente a cefadroxilo desde el alta en espera de los resultados del estudio de micobacterias y hongos. La ausencia de dolor y signos inflamatorios impidió evaluar una respuesta sintomática. La tinción de Ziehl-Neelsen fue negativa en la muestra operatoria y el cultivo para micobacterias en medio líquido fue negativo luego de 42 días de incubación. En el cultivo corriente de la muestra obtenida en el aseo quirúrgico se observó el desarrollo de un hongo filamentoso, siendo derivada al Laboratorio de Micología de la Universidad Austral de Chile. El subcultivo en agar papa dextrosa (BD, EE.UU.) demostró a los siete días una colonia aterciopelada de color marrón con tonalidades de gris, y color oliváceo por el reverso (Figura 2). En la observación microscópica, realizada con azul de lactofenol, se observaron hifas tabicadas pigmentadas, conidióforos con fiálides acampanadas pequeñas y de una tonalidad más oscura que las hifas, con conidios redondos oscuros y ovoides hialinos (Figura 3). El hongo fue identificado como Pleurostomophora richardsiae siendo confirmado por pruebas moleculares. La extracción del ADN se realizó directamente del cultivo realizado en agar papa utilizando el kit PrepMan ${ }^{\mathrm{TM}}$ Ultra (AppliedBiosystems, EE. UU.), de acuerdo con el protocolo del fabricante. La región ITS (internal transcribed spacer region) se amplificó por RPC con los partidores ITS4 e ITS5 y se secuenció con el partidor ITS5. Los productos de la RPC se purificaron y secuenciaron en el laboratorio de Genómica, AUSTRAL-omics (Universidad Austral de Chile, Valdivia, Chile) con un secuenciador ABI3500 (AppliedBiosystems). La secuencia fue analizada con el programa SeqMan ${ }^{\circledR}$ (Lasergene, Madison, Wisconsin, EE. UU.) con el objeto de obtener una secuencia confiable; y a continuación se realizó una búsqueda BLASTn de ésta (533 pb de longitud). Los porcentajes de identidad obtenidos oscilaron entre 99 y $85 \%$ de identidad con las siguientes cepas tipo depositadas en la colección de cultivos del Westerdijk Fungal Biodiversity Institute (antiguo CBS, Utrecht, Holanda) como sigue: Pleurostomophora richardsiae CBS 270.33 (99\%, código acceso NR135933), Pleurostomophora repens CBS 294.39 (86\%, código acceso NR135925) y Pleurostomophora ochraceum CBS 131321 (85\%, código acceso NR136033), respectivamente.

Por otra parte, el estudio histológico de la muestra reveló un proceso inflamatorio crónico con granulomas con empalizadas de histiocitos, con células gigantes y células linfoides y plasmocitos, rodeando un material amorfo eosinófilo tipo detritus celular y fibrinoide (Figura 4). En otras zonas, se apreciaban nódulos compuestos de vasos de neoformación, glóbulos rojos, células inflamatorias, histiocitos y células gigantes multinucleadas, con presencia de macrófagos con hemosiderina citoplasmática. Los estudios con tinciones de Ziehl-Neelsen, Gomori-Grocott y Fontana- Masson fueron negativas, pero en la tinción de PAS se observaron algunas hifas (Figura 4).

El paciente fue dado de alta a las dos semanas de la cirugía y falleció en su casa en forma súbita a los tres meses, sin evidencias de un cuadro séptico asociado. Se presumió, por la edad del paciente y sus antecedentes, un deceso de causa cardiovascular. La identificación del hongo fue lograda postmortem sin que el paciente recibiera tratamiento específico. 


\section{Caso Clínico}

\section{Discusión}

Varios hechos inusuales se manifestaron en nuestro paciente que lo distinguen de los casos habituales de infecciones de piel y tejidos blandos. Entre ellos destaca un aumento de volumen insidioso en extremidades, sin signos inflamatorios locales, el compromiso subcutáneo, la escasa repercusión sistémica a pesar de la extensión de la lesión, la existencia de espacios tabicados y el hallazgo de granulomas en el estudio histológico con presencia de hifas. Destaca además, la existencia de secreción a través de una fístula cutánea y la ausencia de diseminación a distancia o adenopatías regionales. Las posibilidades etiológicas para este tipo de comportamiento (absceso frío con o sin supuración en una extremidad) son reducidas y principalmente restringidas a hongos dematiáceos productores de melanina, micetomas bacterianos o fúngicos y algunas micobacterias ${ }^{9-11}$. Los tumores de tejidos blandos, benignos o malignos, son también parte del diagnóstico diferencial.

Los hongos dematiáceos, negros o pigmentados, son un grupo heterogéneo que tienen en común la síntesis de melanina o compuestos relacionados. En el ser humano las infecciones por este tipo de hongos, que presentan levaduras o hifas tabicadas en los tejidos, se denominan feohifomicosis e incluyen queratitis, cuadros cutáneos superficiales, subcutáneos o de naturaleza invasora como neumonía, endocarditis o abscesos cerebrales, afectando tanto pacientes inmunocompetentes o inmunocomprometidos $^{12-21}$.

Las feohifomicosis se asocian a varias especies fúngicas, siendo las más frecuentes Alternaria sp, Bipolaris sp, Cladophialophora sp, Curvularia sp y Pleurostomophora sp (previamente Phialophora). Son hongos ambientales que viven en el suelo y en material en descomposición. Se asume que la infección se contrae por un trauma local, pero este antecedente no está presente en todos los casos. En nuestro paciente, el trauma autoinflingido fue posterior a la aparición del cuadro clínico.

El diagnóstico de una feohifomicosis se puede sospechar por un cuadro clínico compatible de tipo indolente en una extremidad, sin síntomas sistémicos y en ausencia de inflamación local o adenitis regional, pruebas de laboratorio no alteradas y ocasionalmente secreción por una fístula. En apoyo al diagnóstico concurre la detección de colecciones cutáneas de aspecto quístico en el estudio de imágenes, la presencia de granulomas con o sin presencia de hifas en tinciones complementarias y finalmente la identificación microbiológica por cultivos ${ }^{13,15,18-21}$. La identificación por amplificación y secuenciación es una estrategia complementaria que ha sido aplicada progresivamente en años recientes y que fue utilizada en nuestro caso $^{12,17,18,20}$.

Revisamos casos publicados de infecciones por $P$.

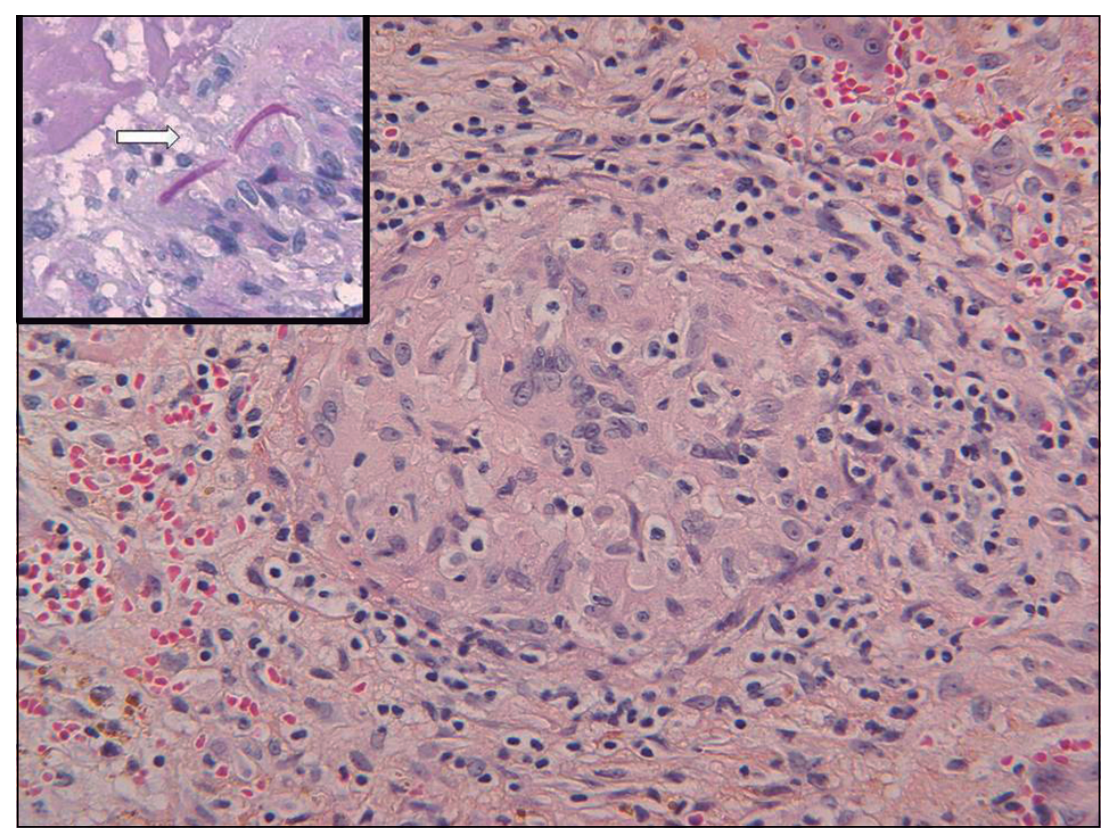

Figura 4. Microfotografía de inflamación crónica con granuloma en el centro, compuesto de histiocitos y una célula gigante multinucleada (hematoxilina-eosina, 400x). En el inserto, hifas en tinción PAS.

richardsiae desde los años 90 y rescatamos algunos antecedentes para identificar rasgos comunes (Tabla 1). Los casos afectan principalmente a pacientes de sexo masculino en edad media o tercera edad. Predominan reportes del hemisferio norte en pacientes inmunocompetentes o inmunocomprometidos, incluyendo en el último caso a pacientes sometidos a trasplante de órganos sólidos o terapia corticoesteroidal. El espectro clínico incluye infecciones de tejidos blandos, endocarditis o fungemia, endoftalmitis o infección del saco lacrimal (Tabla 1) 12,13,16-18,20-24. El tratamiento ha contemplado compuestos antifúngicos en monoterapia o combinaciones y aseo quirúrgico.

El tratamiento óptimo de las infecciones por P. richardsiae no ha sido definido. Los casos publicados han señalado terapias exitosas con la resección quirúrgica del sitio afectado o tratamiento farmacológico con una variedad de compuestos tales como itraconazol, anfotericina B deoxicolato o liposomal $1^{15,21,23}$. Estudios ocasionales de actividad in vitro han revelado concentraciones inhibitorias mínimas de $0,5 \mu \mathrm{g} / \mathrm{ml}$ para anfotericina $\mathrm{B} ; 1 \mu \mathrm{g} / \mathrm{ml}$ para itraconazol y posaconazol y $2 \mu \mathrm{g} / \mathrm{ml}$ para voriconazol ${ }^{20}$. Otros estudios han revelado valores similares o menores ${ }^{23}$. La actividad de fluconazol $(128 \mu \mathrm{g} / \mathrm{ml})$ y equinocandinas ( $>8 \mu \mathrm{g} / \mathrm{ml}$ para micafungina, caspofungina y anidulafungina) es menor ${ }^{20}$.

El pronóstico de esta infección es en general, favorable (Tabla 1). 


\begin{tabular}{|c|c|c|c|c|c|c|c|}
\hline & País, año & Sexo, Edad & $\begin{array}{l}\text { Situación inmune y } \\
\text { comorbilidad }\end{array}$ & Cuadro clínico & Tratamiento & Desenlace & Referencia \\
\hline 1 & Tailandia, 2019 & $M, 57$ & Trasplante hepático & Fungemia, hepatitis & Anfotericina B deoxicolato & Mejora & 20 \\
\hline 2 & Reino Unido, 1994 & $M, 54$ & Trasplante renal & $\begin{array}{c}\text { Absceso falange mano y } \\
\text { rodilla }\end{array}$ & Aseo quirúrgico & Mejora & 15 \\
\hline 3 & Nueva Zelandia, 2004 & $M, 45$ & Trasplante renal & Lesión subcutánea pie & $\begin{array}{c}\text { Aseo quirúrgico + anfotericina } \\
\text { B liposomal + itraconazol }\end{array}$ & Mejora & 21 \\
\hline 4 & Japón, 2017 & $M, 78$ & $\begin{array}{l}\text { Quimioterapia reciente } \\
\text { por cáncer de prostata }\end{array}$ & Quiste subcutáneo crural & $\begin{array}{c}\text { Calor local + anfotericina B } \\
\text { deoxicolato intralesional }\end{array}$ & Mejora & 18 \\
\hline 5 & Holanda, 2016 & $F, 75$ & $\begin{array}{c}\text { Metotrexate }+ \text { prednisona } \\
\text { por artritis reumatoidea }\end{array}$ & Lesión en brazo & $\begin{array}{l}\text { Aseo quirúrgico, voriconazol y } \\
\text { reducción inmunosupresion }\end{array}$ & $\begin{array}{l}\text { Fallece por causa } \\
\text { no relacionada }\end{array}$ & 22 \\
\hline 6 & Reino Unido, 1993 & $M, 52$ & Diabetes mellitus & $\begin{array}{l}\text { Endocarditis válvula } \\
\text { protésica con endoftalmitis }\end{array}$ & $\begin{array}{l}\text { Anfotericina } B \text { deoxicolato + } \\
\text { reemplazo valvular }\end{array}$ & $\begin{array}{l}\text { Fallece por } \\
\text { complicaciones } \\
\text { tardías }\end{array}$ & 16 \\
\hline 7 & Estados Unidos, 2003 & $M, 77$ & Sin antecedentes & Bursitis rodilla & $\begin{array}{c}\text { Anfotericina B deoxicolato + } \\
\text { itraconazol }\end{array}$ & Mejora & 23 \\
\hline 8 & Canadá, 2012 & $M, 74$ & Sin antecedentes & Nódulo subcutáneo patelar & Rechaza tratamiento & $\begin{array}{l}\text { Estable en } \\
\text { seguimiento }\end{array}$ & 17 \\
\hline 9 & Estados Unidos, 2017 & $M, 43$ & Sin antecedentes & Endoftalmitis & $\begin{array}{c}\text { Anfotericina B deoxicolato } \\
\text { intravítreo + anfotericina B y } \\
\text { voriconazol ev. }\end{array}$ & $\begin{array}{l}\text { Fallece por causa } \\
\text { no relacionada }\end{array}$ & 13 \\
\hline 10 & India, 2017 & $F, 35$ & Sin antecedentes & Masa saco lagrimal & Drenaje local & Mejora & 24 \\
\hline 11 & España, 2018 & $M, 75$ & Sin antecedentes & Nódulo subcutáneo mano & Aspiración & Mejora & 12 \\
\hline 12 & Chile, 2020 & $M, 86$ & Sin antecedentes & Masa subcutánea mano & Aseo quirúrgico & $\begin{array}{l}\text { Fallece por causa } \\
\text { no relacionada }\end{array}$ & Este reporte \\
\hline
\end{tabular}

No creemos que el desenlace abrupto del paciente haya estado relacionado con la infección fúngica debido al buen pronóstico de estas infecciones reportado en la literatura especializada, al curso indolente previo, al aseo quirúrgico efectuado y a la posibilidad por la edad, de una muerte súbita de origen cardiovascular.

En conclusión, $P$. richardsiae es un hongo dematiáceo ambiental, capaz de provocar infecciones de tejidos blandos o invasoras en pacientes inmunocompetentes o inmunocomprometidos. Cuando afecta estructuras blandas, se asocia a un cuadro clínico indolente, con escasa respuesta inflamatoria local. El diagnóstico se obtiene mediante cultivo de hongos, en ocasiones con el auxilio de secuenciación genética. El estudio histopatológico muestra granulomas con presencia de hifas que facilitan la sospecha. El tratamiento no está estandarizado e incluye aseo quirúrgico y/o compuestos antifúngicos tales como anfotericina $\mathrm{B}$, itraconazol o voriconazol.

\section{Referencias bibliográficas}

1.- Breyre A, Frazee B W. Skin and soft tissue infections in the Emergency Department. Emerg Med Clin North Am 2018; 36: 723-50. doi: 10.1016/j.emc.2018.06.005.

2.- Chira S, Miller L G. Staphylococcus aureus is the most common identified cause of cellulitis: a systematic review. Epidemiol Infect 2010; 138: 313-7. doi: 10.1017/S0950268809990483

3.- Türker T, Capdarest-Arest N, Bertoch S T, Bakken E C, Hoover S E, Zou J. Hand infections: a retrospective analysis. Peer J 2014;
2: e513. doi: 10.7717/peerj.513.

4.- Charalambous C P, Zipitis C S, Kumar R, Lipsett P A, Hirst P, Paul A. Soft tissue infections of the extremities in an orthopaedic centre in the UK. J Infect 2003; 46: 106-10. doi: 10.1053/jinf.2002.1099.

5.- Aubry A, Mougari F, Reibel F, Cambau E. Mycobacterium marinum. Microbiol Spectr 2017; 5 (2). doi: 10.1128/microbiolspec. TNMI7-0038-2016.

6.- Chang-Chien C H, Ding H T, Liu C, Yang C S. Vibrio infection associated with finning injury of the hand. Injury 2007; 38: 614-8. doi: 10.1016/j.injury.2006.04.134.

7.- González M H, Bochar S, Novotny J, Brown A, Weinzweig N, Prieto J. Upper extremity infections in patients with diabetes mellitus. J Hand Surg Am 1999; 24: 682-6. doi: 10.1053/ jhsu.1999.0682.

8.- Ulloa M T, Giglio M S, Porte L, Santa Cruz A, McNab P, Fica A, et al. Detección de los genes de las exotoxinas pirogénicas de SpeA, SpeB y SpeC en cepas chilenas de Streptococcus pyogenes y su relación con la clínica. Rev Med Chile 2000; 128: 27-34. doi: 10.4067/S003498872000000100004 . 
9.- Filippi J, Quezada F, Lagos M, García P. Micetoma por Actinomadura madurae en el pie. Reporte de un caso en Chile. Rev Med Chile 2008; 136: 1448-52. doi: 10.4067/S003498872008001100011.

10.- Soto Silva A, Porte Torre L, Dabanch Peña J, Braun Jones S. Lesión cutánea de larga evolución en paciente inmunocompetente. Enferm Infecc Microbiol Clin 2013; 31: 55556. doi: 10.1016/j.eimc.2013.03.009.

11.- Fica A, Soto A, Dabanch J, Porte L, Castro M, Thompson L, et al. Micobacterias atípicas en cinco pacientes adultos sin evidencias de inmunosupresión. Construyendo una experiencia. Rev Chilena Infectol 2015; 32: 80-7. doi: 10.4067/S071610182015000200012 .

12.- Cuenca-Barrales C, De Salazar A, Chueca N, Saenz-Guirado S, Ruiz-Villaverde R. Phaeohyphomycosis due to Pleurostomophora richardsiae: an uncommon cutaneous fungal Infection. J Eur Acad Dermatol Venereol 2018; 32: e376-e377. doi: 10.1111/jdv.14943.

13.- Fox A R, Houser K H, Morris W R, Walton R C. Dematiaceous fungal endophthalmitis: report of a case and review of the literature. J Ophtalmic Inflamm Infect 2016; 6:43. doi: 10.1186/s12348-016-0111-2.

14.- Fica A, Díaz M C, Luppi M, Olivares R, Saez L, Baboor M, et al. Unsuccessful treatment with voriconazol of a brain abscess due to Cladiophialophora bantiana. Scan J Infect Dis 2003; 35: 892-93. doi: 10.1080/00365540310016736.

15.- Jumaa P A, Lightowler C, Baker L R, Das S S. Cutaneous infection caused by Phialophora richardsiae treated successfully by surgical excision in an immunocompromised patient. J Infect 1995; 30: 261-2. doi: 10.1016/s01634453(95)90877-3.

16.- Juma A. Phialophora richardsiae endocarditis of aortic and mitral valves in a diabetic man with a porcine mitral valve. J Infect 1993; 27 : 173-5. doi: 10.1016/0163-4453(93)94782-7.

17.- Levenstadt J S, Poutanen S M, Mohan S, Zhang S, Silverman M. Pleurostomophora richardsiae - an insidious fungus presenting in a man 44 years after initial inoculation: A case report and review of the literature. Can J Infect Dis Med Microbiol 2012; 23: 110-13. doi: $10.1155 / 2012 / 406982$.

18.- Noguchi H, Hiruma M, Matsumoto T, Yaguchi T, Sano A, Mitsui N, et al. Subcutaneous cystic phaeohyphomycosis due to Pleurostomophora richardsiae. J Dermatol 2017; 44:e62-e63. doi: 10.1111/1346-8138.13765.

19.- Singh S M, Agrawal A, Naidu J, de Hoog G S, Figueras M J. Cutaneous phaeohyphomycosis caused by Phialophora richardsiae and the effect of topical clotrimazole in its treatment. Antonie van Leeuwenhoek 1992; 61: 51-55. doi: 10.1007/BF00572122.
20.- Sribenjalux W, Chongtrakool $\mathrm{P}$, Chayakulkeeree M. Disseminated phaeohyphomycosis with hepatic artery and portal vein thrombosis caused by Pleurostomophora richardsiae in a liver transplant recipient: A case report. Transpl Infect Dis 2019; 21: e13075. doi: 10.1111/ tid.13075.

21.- Yehia M, Thomas M, Pilmore M, Van Der Merwe W, Dittmer I. Subcutaneous black fungus (phaeohyphomycosis) infection in renal transplant recipients: three cases. Transplantation 2004; 77: 140-2. doi: 10.1097/01.TP.0000107287.70512.E7.

22.- De Regt M J, Murk J L, Schneider-Hohendorf T, Wattjes M P, Hoepelman A I M, Arends J E. Progressive multifocal leukoencephalopathy and black fungus in a patient with rheumatoid arthritis without severe lymphocytopenia. JMM Case Rep 2016; 3: e005053. doi: 10.1099/ jmmcr.0.005053.

23.- Cornia P B, Raugi G J, Miller R A. Phialophora richardsiae bursitis treated medically. Am J Med 2003; 115:77-9. doi: 10.1016/s00029343(03)00287-0.

24.- Alam S, Vaidehi D, Therese K L, Ali M J. Rare Pleurosthomophora richardsiae mass causing transient nasolacrimal duct obstruction. Ophthalmic Plast Reconstr Surg 2017; 33: e154-e156. doi: 10.1097/ IOP.0000000000000919. 